\title{
Trabalho de mulheres ${ }^{1}$
}

\author{
Susan Bassnett* \\ Tradução de Letícia Horta**2
}

Li recentemente uma nova tradução da grande coletânea galesa de 11 contos medievais, conhecidos, quando reunidos, como The Mabinogion. Já havia lido uma versão antes, mas essa tradução, publicada em 2008, é muito boa de ler, provavelmente porque a tradutora levou em consideração o fato de que os contos originais eram lidos em voz alta para um público, e por isso tentou enfatizar o aspecto performático das obras. A tradutora é Sioned Davies, professora de galês na Universidade de Cardiff, e com essa nova tradução, ela seguiu os passos de outra tradutora célebre: Charlotte Guest.

Lady Charlotte Guest passou vários anos, de 1838 a 1846, traduzindo contos galeses para o inglês. Esse grande trabalho incluiu notas detalhadas e serviu como tradução padrão por décadas. De fato, pode ser argumentado que a tradução de Guest trouxe notoriedade à literatura medieval galesa num momento histórico importante, quando os movimentos revolucionários espalhados pela Europa se voltavam para as suas origens literárias como uma maneira de estabelecer a sua identidade nacional.

Lady Charlotte não cresceu falando galês; ela aprendeu a língua mais tarde, depois de casada, mas estava empenhada em utilizar a tradução como um meio de gerar conhecimento sobre a grandeza de uma literatura que julgava negligenciada. Talvez ela não seja tão famosa quanto Lady Augusta Gregory, que apresentou canções e histórias tradicionais irlandesas para

\footnotetext{
1 Originalmente publicado em BASSNETT, Susan. Reflections on Translation. Toronto: Multilingual Matters, 2014, p. 94-97.

* Universidade de Glasgow e Universidade de Warwick

${ }^{* *}$ Bacharelado em Letras - Tradução (Inglês-Português), PUC-Rio

${ }^{2}$ Revisão de Marcia A. P. Martins (PUC-Rio) e Breno Lucas Santos (UERJ)
} 
novos públicos dentro e fora da Irlanda, mas a tarefa que Lady Charlotte assumiu é de igual importância. Ela tinha, de fato, talento para línguas, e antes de virar sua atenção para o galês, aprendeu árabe e hebraico sozinha.

Quando começamos a examinar a história das literaturas no que diz respeito à tradução, é interessante ressaltar o papel desempenhado pelas tradutoras, cujo trabalho amiúde teve imenso impacto, embora sua contribuição seja, de modo geral, pouco valorizada, e seus nomes, muitas vezes esquecidos. Uma dessas traduções, que muito influenciou o romance inglês, foi feita por Constance Garnett, que produziu 71 volumes de literatura russa traduzida, um número impressionante. O seu interesse pelo russo começou quando estava estudando literatura clássica no Newnham College, em Cambridge, e cresceu ao longo do tempo. Viajou para a Rússia, conheceu Tolstói em 1893 e, por causa dos seus esforços, toda uma geração de leitores britânicos se familiarizou com os grandes nomes da literatura russa ainda não descoberta. No entanto, quando ouço alguém comentar que leu Guerra e Paz ou Anna Karenina, o nome de Constance Garnett nunca é mencionado, e sem ela, Tolstói teria continuado inacessível por décadas.

Uma rápida análise da história da tradução literária revela uma longa lista de nomes de tradutoras talentosas. O rei anglo-saxão, Alfred, que foi um dos primeiros tradutores, foi educado nas artes literárias pela mãe, e ao longo dos séculos, um grande número de mulheres inteligentes praticaram a tradução. Durante a Renascença e a Reforma Protestante, muitas mulheres traduziram obras antigas e textos sagrados, dentre elas Lady Mary Sidney e a filha de São Thomas More, Margaret Roper. Elisabete I traduziu ao longo de toda a sua vida; aos 11 anos de idade, presenteou sua madrasta, Catherine Parr, com uma tradução de The Glass of the Sinful Soul, uma obra da rainha francesa Margarida de Navarra. Ela realçou o presente providenciando uma capa bordada com flores roxas. Na velhice, traduziu Boécio; a prática da tradução para ela era uma clara oportunidade de colocar em prática a sua criatividade, e também era, provavelmente, uma atividade que a distraía e gratificava, uma folga dos problemas do Estado.

A razão pela qual as mulheres começaram a atuar como tradutoras durante a Renascença já foi muito debatida. Uma escola de pensamento interpreta esse fenômeno como uma indicação do baixo status da tradução e 
das próprias mulheres na sociedade; elas podiam traduzir porque a tradução era vista como uma atividade marginal. Uma visão alternativa rejeita essa interpretação, argumentando que a tradução na Renascença era tudo menos marginal, e de fato traduzir teve imensa importância - William Tyndale e Etienne Dolet foram condenados à fogueira por causa de traduções subversivas e heréticas. O estudioso da tradução estadunidense Douglas Robinson (1995) sugere que esse foi um período em que as mulheres começaram a utilizar as traduções como uma maneira de adquirir uma voz pública. Robinson chama isto de "feminização" da tradução, e a sua teoria parece fazer sentido quando olhamos para a relação entre as mulheres e a tradução ao longo do século XVII e posteriormente. Muitas escritoras famosas traduziam, de Aphra Behn a Mary Wollstonecraft, de Madame de Staël a George Eliot. Mulheres produziam traduções de peças de teatro, poemas, romances, textos filosóficos e tratados científicos. Elas estiveram sobremodo envolvidas em trabalhos de tradução comercial desde o século XVII, provendo os editores com manuscritos traduzidos de línguas antigas e modernas, e se mostraram particularmente ativas no século XVIII no que tange às traduções teatrais. No século XIX, a filha de Karl Marx, Eleanor, traduziu Madame Bovary, de Flaubert, um romance imputado de imoral na França. As mulheres na Inglaterra da rainha Vitória traduziram obras do escandaloso Emile Zola e do chocante Henrik Ibsen. A tradução parecia oferecer uma oportunidade às mulheres de se libertarem do papel tradicional de "anjo da casa" e de falar, muitas vezes de forma radical, por meio da obra de outro escritor.

Uma pergunta que os estudantes sempre fazem - que eu também fiz quando estava na universidade, e que hoje em dia surge com a mesma frequência - é se podemos distinguir gênero na escrita. Em outras palavras, será que homens e mulheres escrevem de forma diferente, será que seu emprego da linguagem é distinto, será que um leitor, diante de uma obra anônima, consegue detectar o gênero de quem a escreveu, independentemente do tema tratado? Essa questão se torna importante sobretudo quando pensamos em tradução, uma vez que precisamos nos perguntar se uma obra escrita por uma mulher pode ser traduzida de forma adequada por um homem e vice-versa. Algumas tradutoras feministas vêm, 
de fato, argumentando que o gênero de quem traduz um texto deve corresponder ao de quem o produziu.

No entanto, essa abordagem baseia-se em pressupostos instáveis e não comprovados sobre gênero e escrita e, além disso, limita as possibilidades de atuação no campo da tradução. Existem muitos tradutores e tradutoras de talento que simplesmente produzem boas traduções, sem prejuízos decorrentes de questões de gênero. O falecido Giovanni Pontiero produziu belas traduções da escritora brasileira Clarice Lispector. Já Suzanne Jill Levine (1991) não só traduziu de maneira excepcional escritores latino-americanos, todos homens, como também produziu textos elegantes e inteligentes a respeito de suas estratégias tradutórias. Seu livro The Subversive Scribe: Translating Latin American Fiction é um texto clássico que aborda a difícil questão da identidade de gênero na tradução, examinando os problemas que surgem quando uma tradutora feminista precisa lidar com uma escrita misógina. Em tais circunstâncias, ela argumenta, a tradutora torna-se subversiva, mas afinal, explica ela, traduzir, como todas as formas de escrita, envolve a busca da "própria língua" (LEVINE, 1991).

Hoje em dia, existem muitas tradutoras aclamadas. Compilar uma lista com todos os nomes seria impossível - há um bom número de excelentes tradutoras e tradutores que simplesmente produzem boas traduções - e qualquer lista parcial é injusta, mas uma amostra dos nomes de algumas tradutoras cujos trabalhos li ao longo dos últimos anos inclui Margaret Sayers Peden, Amanda Hopkinson, Anthea Bell, Tiina Nunnaly, Ros Schwartz, Josephine Balmer, Carol Maier, Elaine Feinstein e Luise von Flotow, que trabalham com diferentes línguas e gêneros literários, traduzindo escritores e escritoras.

Deixando de lado a questão do gênero de autores/as e tradutores/as, ainda existem, no entanto, questões importantes que decorrem das diferentes maneiras de se marcar o gênero linguisticamente. Línguas como o inglês, que não têm a marcação de gênero na gramática, dão aos escritores a liberdade de brincar com a ambiguidade. A tradutora espanhola da poeta americana Adrienne Rich passou por dificuldades ao traduzir alguns dos poemas de amor de Rich para o espanhol, pois os poemas em questão se referiam a outra mulher, e isso precisava estar evidente na linguagem. 
Myriam Diaz-Diocaretz (1985) escreveu um livro sobre a tradução da poesia de Rich, mostrando como as relações lésbicas que estavam implícitas no inglês original tornaram-se explícitas em espanhol devido à forma como a língua funciona, e discutiu como tal fato causou problemas numa sociedade que era menos tolerante com relacionamentos entre o mesmo sexo. Em uma das minhas traduções, precisei estabelecer o sexo de um bebê logo no início, uma vez que a língua para a qual estava traduzindo não me permitiria manter a ausência de gênero presente na palavra $b a b y$, que em inglês é neutra. Tais decisões afetam a maneira como um poema é lido, mas são inevitáveis, pois a língua-alvo em questão só funciona dessa forma.

Algumas das reflexões mais provocantes e interessantes sobre tradução e gênero vieram de tradutoras canadenses. Em particular, gosto do jogo de palavras de Barbara Godard (1990, p. 94) quando ela escreve sobre "manimulherpulou"3 um texto, algo que ela descreve como sendo a "substituição do tradutor modesto, que se autoapaga". Tradutoras como Godard e Levine foram muito além da questão sobre se o sexo de quem traduz deveria ser o mesmo de quem produziu o texto originário. Elas enfatizam o papel dinâmico de quem traduz, na criatividade da tradução, no fato que para traduzir é necessário ter habilidade e entendimento, e que, acima de tudo, a tradução é um ato de recriação, pois nunca poderá ser igual ao original no qual é baseada. Com isso, como Sherry Simon (1996) explica sucintamente em seu estudo sobre gênero e tradução, ao considerar a tradução como reescrita criativa, pressuposições sobre a supremacia do original sobre a tradução começam a se desmoronar, assim como pressuposições a respeito da supremacia do masculino sobre o feminino, abrindo espaço para que tradutores e tradutoras, independentemente do gênero, afirmem sua própria autoridade autoral e encontrem a sua voz própria e particular.

\footnotetext{
${ }^{3}$ N. T. Solução tradutória para o termo womanhandled adotada em “Anjos/ângulos: da tarefa angelical ao traduzir da mulher", de Barbara Godard, publicado em Revista de Estudos de Literatura (Belo Horizonte, v. 5, p. 155-182, 1997), em tradução de Marília Scaff.
} 